\title{
An approach for recurrent thyroid carcinoma with a clavicle osteotomy
}

\section{Rekürren tiroid karsinomuna klavikula osteotomisi ile yaklaşım}

\author{
Norhafiza Mat Lazim $^{1}$ (, Baharudin Abdullah¹, Wan Faisham Numan Wan Ismail²
}

\begin{abstract}
Papillary thyroid carcinoma (PTC) has a good prognosis and a low recurrence rate. The recurrent disease mainly involves the neck and distant metastases. The current trend is to incorporate prophylactic neck dissection for papillary thyroid carcinoma during the first surgery of papillary carcinoma in order to reduce the risk of recurrence. We are presenting a case of recurrent papillary thyroid carcinoma extending from level $V$ neck node to the infraclavicular space. A clavicular osteotomy was performed for a wider surgical access and to attain a better oncological margin. The majority of recurrent neck diseases occurs at central compartment followed by the level III and level IV neck nodes. Reoperation for recurrent neck diseases poses several significant morbidities such as chylous leaks and venous bleeding especially if the tumor is located at the inferior part of inferior jugular vein, at the level IV neck nodes. The clavicular osteotomy provides better surgical access and thus avoids the aforementioned complications. This method is an effective approach for complete removal of a recurrent tumor at the base of the neck with good surgical margin.
\end{abstract}

Keywords: Recurrent papillary thyroid carcinoma, clavicular osteotomy, internal jugular vein, metastatic neck nodes, root of neck öz

Papiller tiroid karsinomu iyi prognoza ve düşük rekürrens oranlarına sahiptir. Rekürren hastalık genellikle boyun ve uzak metastazlar şeklindedir. Günümüzde yaklaşım rekürrens riskini azaltmak için papiller karsinomun ilk cerrahisinde profilaktik boyun diseksiyonunu eklemektir. Biz burada level 5 lenf nodundan infraklavikular alana uzanan rekürren papiller tiroid karsinomu vakasını sunuyoruz. Daha geniş cerrahi alana ulaşmak ve kanser sınırlarına daha iyi hakim olmak için klavikula osteotomisi yaptık. Rekküren boyun hastalıklarının coğunluğu santral bölgede, sonra sırasıyla level 3 ve level 4 lenf nodlarında olur. Level 4 boyun nodlarında, boyun rekürrenslerinin yineleyen cerrahisinde, özellikle tümör internal juguler venin alt kısmında lokalize ise venöz kanamalar ve şiloz sızıntı gibi komplikasyonlar görülebilir. Klavikula osteotomisi bu komplikasyonların oluşumunu önleyen daha iyi bir cerrahi yaklaşım sağlamaktadır. Bu yöntem boyun bazalindeki tümörlerin iyi cerrahi sınır ile tamamen çıkarılması için efektif bir yaklaşımdır.

Anahtar kelimeler: Rekürren papiller tiroid karsinom, klavikular osteotomi, internal juguler ven, metastatik boyun nodlari, boyun kökü

\section{INTRODUCTION}

Head and neck surgery is challenging when dealing with tumor recurrence especially at critical areas involving the major neurovascular structures. The majority of patients who had prior surgery also had adjuvant chemoradiation or radio-iodine ablation which causes significant tissue fibrosis that made the reoperation even more difficult. Papillary thyroid carcinoma is the most common thyroid malignancy

Received: 09.08.2018

Accepted: 21.08 .2018

${ }^{1}$ Department of Otorhinolaryngology-Head \& Neck Surgery, School of Medical Sciences, Universiti Sains Malaysia, Health Campus Kubang Kerian 16150 Kelantan, Malaysia

${ }^{2}$ Department of Orthopaedic, School of Medical Sciences, Universiti Sains Malaysia, 16150 Kota Bharu, Kelantan, Malaysia

Corresponding author: Norhafiza Mat Lazim, Department of Otorhinolaryngology-Head \& Neck Surgery, School of Medical Sciences, Universiti Sains Malaysia, Health Campus Kubang Kerian 16150 Kelantan, Malaysia

e-mail: norhafiza@usm.my

ORCID ID's: 
and generally carries good prognosis with longer survival time. It is characterized by an indolent disease in the majority of cases. However, selected patients with specific clinicopathologic diseases tend to have a poorer prognosis with development of distant metastases. Recurrence of neck diseases occurs in $5-10 \%$ of patients. Liu et al documented that occurrence of neck node metastases is associated with larger tumor size, higher postoperative thyroglobulin levels, advanced TNM stage, higher recurrence rate, and higher disease specific mortality ${ }^{1}$. This recurrence of neck disease mostly occurs at level VI or central compartment of the neck. Some centers routinely adopt prophylactic neck dissection during total thyroidectomy. For instance, most of the Japan institutions advocate prophylactic central compartment neck dissection in contrast to the institutions in the western world. The other pertinent issue in relation to the papillary thyroid carcinoma is the presence of residual micrometastasis at the thyroid bed or in a case of the tumor capsule is breached during the surgery which causes accumulation of metastatic deposits at the surgical bed area. This deposit of micrometastases is a significant factor that leads to the disease recurrence. Chang et al stated that a higher lymph node ration (LNR) which is the ratio of the number of metastatic lymph nodes to the total number of lymph nodes retrieved was associated with recurrence of PTC after initial surgery. They further highlighted that there is a need to analyze the accuracy of prediction of the prognosis depending on whether or not micrometastases were included in the number of metastatic lymph nodes when calculating LNR ${ }^{2}$. Several literatures have discussed that the LNR has emerged as an alternative nodal staging system but not related to the micrometastases. Generally, the micrometastasis is further managed with the added adjuvant radioiodine ablation. This is however hampered by several factors namely correct timing, adequate dose, as well as factors that influence the absorped dose of radiation for overall optimal outcomes. We highlighted a case of papillary thyroid carcinoma that had a double recurrent at the left neck where neck dissections were carried out in combination with the clavicular osteotomy.

\section{Case History}

A 61-year-old Malay lady initially presented with a complaint of anterior neck swelling in 2010. Fine Needle Aspiration Cytology (FNAC) and ultrasound results showed that it was papillary thyroid carcinoma. Subsequently, she underwent total thyroidectomy in August 2010 and then she also received radioiodine ablation for five times with a total dose of 500 mci from 2010 to 2014. At the same time, patient also had a complaint of a persistent cough associated with hoarseness since 2010. There was however no history of night sweat or history of contact with pulmonary tuberculosis (PTB) patients. The endoscopic examination of larynx revealed a bowing right vocal cord with a minimal phonatory gap. A follow-up CT scan in 2012 showed presence of left level la and Ib neck nodes, right jugular nodes and suspicious lung nodules at right apical lung lobes. Subsequently, PET-CT was done in March 2013 and revealed lung metastases. She was suggested to continue with her radioiodine ablation treatment.

However, during follow-up at the clinic in June 2014, clinical examination revealed that she had left neck nodes at level IV and a repeat FNAC confirmed that it was metastatic papillary thyroid carcinoma. Hence, clearance of all lymph nodes level I to level $\mathrm{V}$ of the left neck, ie Modified Radical Neck Dissection (MRND) type I was performed on December 2014. Postoperatively, she continued with her ablation therapy. However, the patient came again in 2016 with left neck swelling at level IV and the supraclavicular area that extends to the clavicle (Figure 1). Examination revealed left level IV nodes measuring $5.0 \mathrm{~cm} \times 4.0$ $\mathrm{cm}$, hard in consistency and fixed to the underlying structures. The FNAC done confirmed that it was a metastatic carcinoma. Repeat CT scan on August 2016 showed presence of a left supraclavicular mass that compressed both the left subclavian vein and internal jugular vein (Figure 2).

After discussing the patient with the nuclear physician, we concluded that the radioactive iodine ablation failed and a consensus was reached for an ap- 


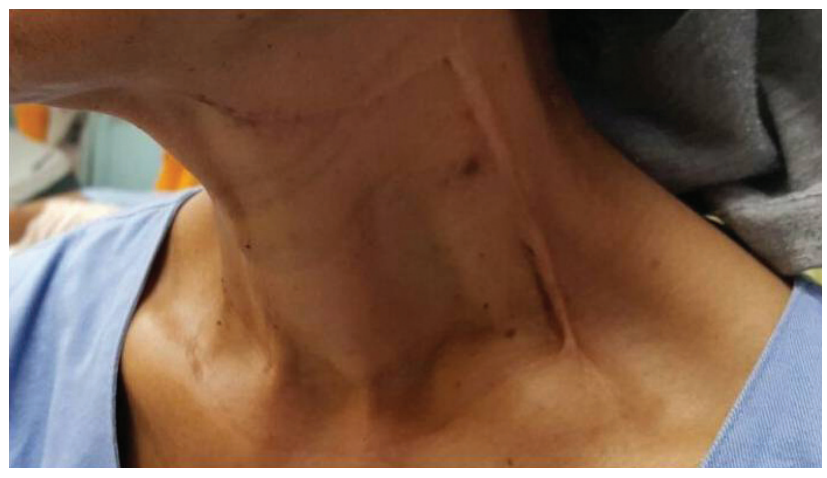

Figure 1. Left neck mass at supraclavicular region with postoperative scarring superiorly.

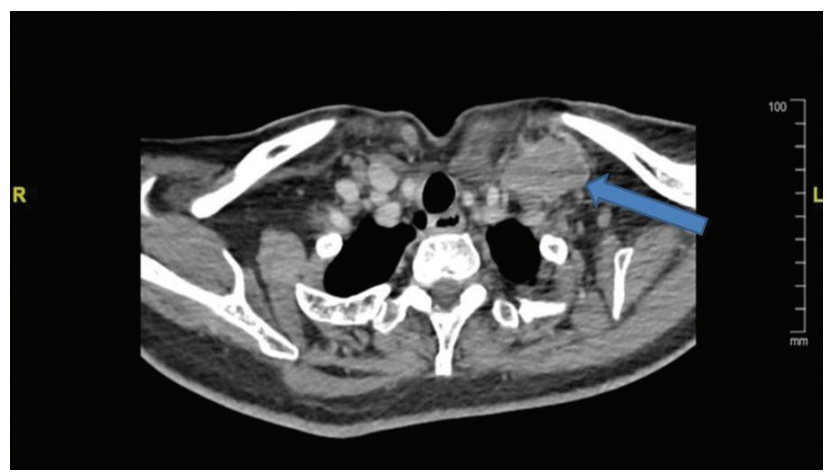

Figure 2. СT scan of the neck showing a heterogenous and a round tumor mass abutting the subclavian vein and internal jugular vein.

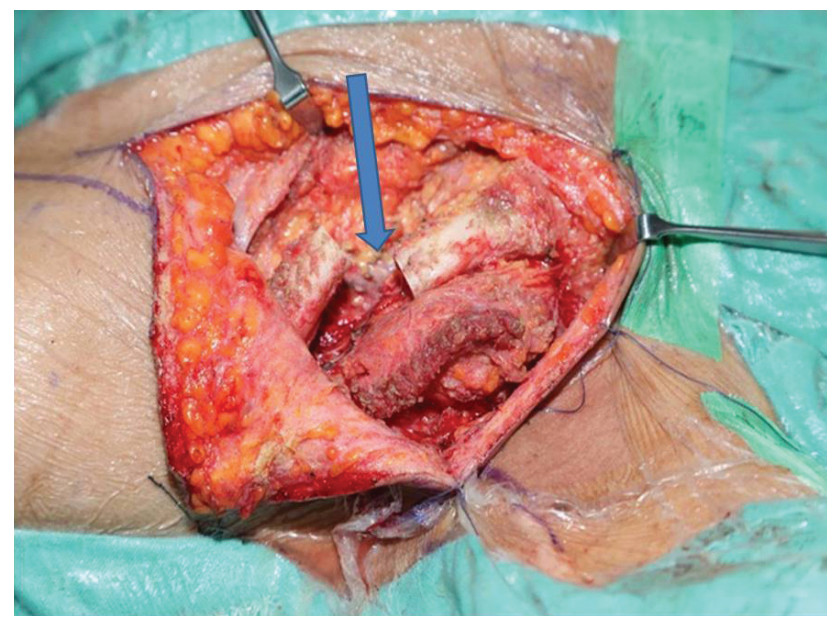

Figure 3. Clavicle osteotomy has been done which will facilitates tumor removal deep to the clavicle after mobilizing the neurovascular structures.

plication of surgical tumor clearance. A combined meeting with the orthopedic team was scheduled and an agreement was obtained indicating that the best approach for the tumor clearance was to do a clavicular osteotomy for maximal exposure in view of the proximity of the tumor to the left subclavian vein and internal jugular vein.

Intraoperatively, the platysma muscle was reflected superiorly to expose the entire mass and clavicle. Surgical access to the tumor at the infraclavicular spaces was achieved by detaching the pectoralis major and minor muscles. Subsequently, the subclavian vein and artery were identified and mobilized inferiorly from the tumor mass. To get the entire medial and lateral marginal control of the mass, the clavicle was osteotomized at the middle segment and reflected subperiosteally (Figure 3 ). The entire mass was removed in total with a cuff of normal tissue to achieve wide resection with an oncological margin. After complete removal of the tumor mass, the clavicle was reapproximate with screw and plate. Homeostasis was secured and skin was closed in two layers.

Postoperatively patient continues with her radioiodine ablation therapy and doing well at her last follow up. Another PET scan was planned for the assessment of local disease and lung metastases. 


\section{DISCUSSION}

Papillary thyroid carcinoma (PTC) has better prognosis compared to other head and neck tumors. It has a high curable rate of $85 \%$ in all cases because of its indolent biologic behavior ${ }^{3}$. The standard management of papillary thyroid carcinoma includes total thyroidectomy in addition to the adjuvant radioiodine ablation therapy given for control of the microscopic diseases. Some centers advocate prophylactic central compartment neck dissection during total thyroidectomy. In $\mathrm{N}$ plus disease central compartment in combination with lateral neck dissection is practiced depending on the sizes and multiplicity of the neck nodes. Even though the survival rate for papillary thyroid carcinoma is excellent, the disease recurrence occurs in up to $30 \%$ of the cases especially in the central and lateral compartment of the neck ${ }^{4}$.

The risk stratification of papillary thyroid carcinoma is important as it gives the overall prognosis for this subset of patients. The prognostic factor for papillary thyroid carcinoma includes the tumor size, the grade, histology subtypes, the patient's age at diagnosis and the presence of lymph nodes metastasis at the initial diagnosis. The older age at diagnosis and male gender portend poorer prognosis. The larger tumor size, extrathyroidal tumor extension, tumor multifocality, cervical lymph node metastases and distant metastases have been shown to associate with higher subsequent recurrences ${ }^{5}$.

The disease relapse of the PTC can occur in isolation or in combination of three different forms. This could be in the form of the lymph nodes metastases, local soft tissue recurrence and distant metastases. Generally, the lymph nodes metastases occur initially in the central compartment, and later spread to Level III and Level IV neck nodes. They are often small and mostly missed by the surgeons in $50 \%$ of the cases ${ }^{6}$. The central compartment is by definition bordered by carotid artery laterally, hyoid bone superiorly and sternal notch inferiorly. The presence of central compartment metastasis is always difficult to assess because in the majority of cases, the smaller nodes located in a deep seated area. The ultrasound and CT scan do not normally yield high sensitivity and specificity in detecting the neck recurrence. It has to be supplemented with intraoperative findings that sometimes require frozen section for the confirmatory of the metastatic nodes.

Ito et al highlighted that three factors that are strongly predicted the recurrence of lymph nodes include the clinical lymph nodes metastases, a large tumor and presence of an extrathyroidal extension? The size of node metastases $3.0 \mathrm{~cm}$ or larger is significantly associated with recurrence of nodes. They suggested a meticulous and extensive lymph nodes dissection and close follow-up with ultrasonography of patients having these three criteria. With the advent of the high-resolution ultrasound, recombinant TSH and highly sensitive thyroglobulin tests, the disease relapse and recurrence can even be discovered at subclinical stage ${ }^{3}$.

We described a case of recurrent papillary carcinoma with node metastases at the Levels IV and V of the neck which located between the left subclavian vein and internal jugular vein that mandates a clavicular osteotomy in order to provide adequate surgical access, to remove the tumor safely. This was imperative because it was a reoperated case with post radioiodine ablation with significant tissue fibrosis that can result in unwanted complications such as the chyle leaks, venous bleeding and inadvertent injury to the surrounding intimate neurovascular structures such as the vagus nerve, brachial plexus and the internal jugular vein.

The surgical access to the base of the neck has several important criteria that need to be taken into consideration by the treating surgeons. The relevant surgical field that contains important neurovascular structures namely the subclavian vessels, spinal accessory nerves, vagus nerve, internal jugular veins and the brachial plexus provides a restricted access. The presence of tumor in this narrow area, further decreases the surgical field poses difficulties during 
surgical access with potential complications, during en bloc removal of the tumor with free surgical margin. The pressure from the tumor in this constricted space can subsequently result in tumor infiltration into the brachial plexus, the subclavian vessels and the surrounding tissues. The deep muscles of the neck also contribute to the difficult surgical access to these areas. Its attachment need to be released for a better exposure and better tumor clearance. In selected cases, like our case the anterior compartment can be widened by clavicular osteotomy so that the major neurovascular structures and muscles can be mobilized without compromising the oncological tumor clearance.

In few selected cases, total removal of the clavicle is also feasible to provide an excellent exposure and preserve all important neurovascular structures at the root of neck. This provides good access to the subclavian vein, the costocervical trunk, dorsal scapular artery, supraclavicular part of brachial plexus, common carotid artery, internal jugular vein, vagus nerve and the phrenic nerve ${ }^{8}$.

The clavicular osteotomy is frequently performed in treating the bony pathology of the clavicle or as an approach to the neck and upper chest tumor. Traditionally, the osteotomy was performed for instance for the treatment of the malunion of the clavicle or to release the compression on branchial plexus. For instance, Hileen et al showed that the corrective osteotomy should be performed in a symptomatic malunion of the clavicle after the midshaft fracture and the results are encouraging. The surgical indications for treating symptomatic malunion of the clavicle includes clavicle shortening more than $1 \mathrm{~cm}$, angulation more than 30 degrees, symptomatic thoracic outlet syndrome, easy fatiguability or pain on repetitive movements and significant disability ${ }^{10}$. The other indication for the clavicular osteotomy includes profuse bleeding from under clavicle, upper trunk or supraclavicular lesion or retroclavicular stretch injuries of the brachial plexus ${ }^{11}$. This transclavicular approach however has not gained popularity in several centers due to the belief that this osteotomy method might lead to nonunion with possible compression to the reconstructed or repaired brachial plexus by the osseous callus. The standard technique to reapproximate the split clavicle is internal plate fixation for better stabilization and early mobilization. The plate can be fixated at the superior or anterior aspect of the clavicle. The superior fixation can cause patient discomfort, unsightly appearance and in selected cases it may causes pain ${ }^{12}$. Goodenough et al documented that in selected cases of axillary and neck node recurrences which required transclavicular approach, patient had excellent functional outcome after a plate and screw fixation. They further described that even in elderly patient, clavicular osteotomy only cause restriction of shoulder elevation and did not cause functional impairment, and it was considerably safe $^{13}$. Noteworthy, this was a young patient with 2-fold lymph node recurrences that warranted complete clearance of the tumor since the patient was already exhausted of the chemoradiation. Clavicular osteotomy as an approach for a low-lying neck recurrent disease in the vicinity of the subclavicular area provides optimal access to the surgical site. This is pertinent approach in order to remove the tumor with free surgical margin and to avoid damage to the thoracic duct, brachial plexus, vagus nerve, phrenic nerves, the carotid arteries and the internal jugular vein that can cause considerable morbidities to the patient. This approach is a versatile approach and it should be recommended in a case where the tumor has encroached the supraclavicular and subclavicular area or any scapula tumor in order to ensure the completeness of tumor resection with free surgical margins and at the same time to avoid unwanted neurovascular complications.

\section{CONCLUSION}

Papillary thyroid carcinoma is associated with recurrent disease, either locally at the neck or thyroid bed as well as distantly. Neck recurrence can be persistent in selected cases and requires multiple surgical approaches for better treatment outcomes. The neck recurrence at the root of neck poses significant surgical challenges because of its intimate relationship 
with the important major neurovascular structures. A clavicular osteotomy provides an ample and versatile surgical access to the root of neck in order to attain a total clearance of a low-lying tumor in the neck without causing dreadful complications.

\section{Declaration of Interests: No conflict of interest was} declared

\section{REFERENCES}

1. Liu FH, Kuo SF, Hsueh C, Chao TC, Lin JD. Postoperative recurrence of papillary thyroid carcinoma with lymph node metastasis. J Surg Oncol. 2015;112(2):149-54. https://doi.org/10.1002/jso.23967

2. Chang YW, Kim HS, Jung SP, Kim HY, Lee JB, Bae JW, Son GS. Significance of micrometastases in the calculation of the lymph node ratio for papillary thyroid cancer. Ann Surg Treat Res. 2017;92(3):117-22.

https://doi.org/10.4174/astr.2017.92.3.117

3. Grant CS. Recurrence of papillary thyroid cancer after optimized surgery. Gland Surg. 2016;4(1):52-6.

4. Chereau N, Buffet C, Tresallect C, et al. Recurrence of papillary thyroid carcinoma with lateral cervical node metastases: Predictive factors and operative management. Surgery. 2016;50(3):755-62. https://doi.org/10.1016/j.surg.2015.08.033

5. Ito Y, Kudo T, Kabayashi K, et al. Prognostic factors for recurrence of papillary thyroid carcinoma in the lymph nodes, lung and bone: analysis of 5,768 patients with average 10 years follow-up. World J Surg. 2012;36(6):1274-8. https://doi.org/10.1007/s00268-012-1423-5

6. Xing $M$, Westra $W H$, Tufano RP, et al. BRAF mutations predict a poorer clinical prognosis for papillary thyroid cancer. J Clin Endocrinol and Metab. 2005;90(12):6373-9. https://doi.org/10.1210/jc.2005-0987

7. Ito $\mathrm{Y}$, Higashiyama T, Takamura $\mathrm{Y}$, et al. Prognosis of patients with papillary thyroid carcinoma showing postoperative recurrence to the central neck. World J Surg. 2011;35(4):76772. https://doi.org/10.1007/s00268-010-0924-3

8. Hankin $\mathrm{MH}$, Stoller JL. A modified dissection method to preserve neck structures. Anat Sci Edu. 2009;2(4):186-92. https://doi.org/10.1002/ase.98

9. Hileen RJ, Eygendaal D. Corrective osteotomy after malunion of midshaft fractures of the clavicle. Strategies Trauma Limb Reconstr. 2007;2(2):59-61.

10. Sally Corey, Shaw KA, Terry Mueller. Chronic clavicular malunion treated with corrective osteotomy. Austin J Orthopade and Rheumatol. 2016;3(2):1031.

11. Kontautas E, Gerulis V, Varzaityte L, et al. Osteosynthesis of the clavicle after osteotomy in brachial plexus surgery: A biomechanical cadaver study. Medicina (Kaunas). 2015;51(2):112-6. https://doi.org/10.1016/j.medici.2015.02.004

12. Iannotti MR, Crosby LA, Stafford P, et al. Effects of plate location on the stability of midshaft clavicle osteotomies: a biochemical study. J Shoulder Elbow Surg. 2002;11(5):457-62. https://doi.org/10.1067/mse.2002.125805

13. Goodenough J, Martin H, Shaaban H. Combined Ipsilateral neck and axillary lymphadenectomy for metastatic skin cancer: A case series and surgical tips. J Plast Reconstr Aesthet Surg. 2013;66(8):1082-7. https://doi.org/10.1016/j.bjps.2013.04.044

12. Liu FH, Kuo SF, Hsueh C, Chao TC, Lin JD. Postoperative recurrence of papillary thyroid carcinoma with lymph node metastasis. J Surg Oncol. 2015;112(2):149-54.

https://doi.org/10.1002/jso.23967

13. Chang YW, Kim HS, Jung SP, Kim HY, Lee JB, Bae JW, Son GS. Signifcance of micrometastases in the calculation of the lymph node ratio for papillary thyroid cancer. Ann Surg Treat Res. 2017;92(3):117-22. https://doi.org/10.4174/astr.2017.92.3.117 